\title{
Study on the Design and Development of Tourist Commodities in Guangxi Minority Areas Represented by Zhuang
}

\author{
Xueyue Long \\ School of Information Science and Technology \\ Guilin University of Electronic Technology \\ Guilin, China
}

\begin{abstract}
Guangxi is characterized with special natural landscape and rich sightseeing resources, where many minorities gather and especially Zhuang has the most representative ethnical features, and it has accumulated abundant ethnical traditional culture over thousands of years. The application of local ethnical cultural elements in the creative development of tourist commodities has practical significance for the development of regional economy and the protection of traditional culture. The paper takes the design and development of tourist commodities in Guangxi Zhuang area as the research object, elaborates the existing problems in the development of the commodities of feature tourism, and puts forward the strategies of development and the principles of creative design under the background of Zhuang ethnical culture.
\end{abstract}

Keywords-Guangxi Zhuang; tourist commodities; ethnical culture; creative design

\section{INTRODUCTION}

Surrounded by green hills and elegant water, the affluent and beautiful place Guangxi, where many ethnic minorities gather, has cradled its ethnical features, especially represented by the minority Zhuang that leaves abundant ethnical traditional culture for thousands of years. Its precious cultural resources and special cultural and geographical environment have been pregnant with the unique tourism resources in Guangxi. With the development of market economy, tourism quickly becomes one of the key industries in Guangxi, and the development of tourist commodities becomes the hot spot of deeply digging tourism and economic resources. The "18th CPC National Congress" of Chinese Party puts forward "the development of regional development depends on promoting the industrial development". Under this general background, developing local-color industry will become a new economic growth point, and the exploration of ethnical culture in tourism region and the development of tourist commodities in tour regions undoubtedly is the new highlight for the growth of local economy.

Fund Project: "Research on Design of Tourist Commodities with Guangxi Zhuang Features" LX2014662 of Universities and Colleges Humanity, Society and Science Research Project of Guangxi Education Department Of Zhuang Autonomous Region.
II. Practical Significance And CurRent Situation OF CReative Development OF TOURIST Commodities WiTH LOCAL ETHNiCAL CULTURE As MATTERS

It is well-known that Japan and Korean in Asia-Pacific areas regard tourist economy as an industry pillar, and during the economic recovery after WWII, tourist industry makes an indelible contribution for the two countries to stimulating domestic demand. At the present time, the orientation of tourist industry by Japan and Korean, besides of aiming at tour and sightseeing, shall include the manufacture and sales of tourist commodities, so the manufacture of tourism products, along with tourism, also rapidly progresses. Japanese product designers have found that: affected by culture, tourists show different shopping motivations; affected by environment, there are direct transformations on the purchasing desires of tourists; affected by the function and appearance of commodity itself, it may motivate tourists' re-shopping needs and batch-shopping needs. Therefore, so many cities of Japan, relying on geographical advantages and combining traditional festivals with Japanese characteristics, design all kinds of novel themes on "festival market" and create regional culture characteristics for example the famous "sakura tourism diplomacy" of Japan. Korean spares no effort to create "Dragon Boat" festival culture, and all combinations of tourism products are designed surrounding the theme of cultural festivals, regional and folkcustom characteristics and other concepts; on the one hand, by virtue of festivals and activities, Korea creates folk culture atmosphere to attract travelers; on the another hand, through abundant and various with commodities, it attracts the consumption of travelers to multi-dimensionally enrich tourist economy, and successfully turn tourist commodities to foreign affair cards.

The vigorous development way of Japan and Korea tourist industry is worthy of being used for reference, compared with Japanese and Korean famous nationality culture, there have 500 -year culture essences, especially minority areas, culture is colorful especially because of regional and national life characteristics, it's worth to deeply explore and sort out diversified ethnic culture, and once these culture characteristics capture an access point to integrate with markets, it will generate the endless vital forces and create a 
huge commercial value, and relying on its strong mobility, tourist commodities can reflect local cultural characteristics, and have the value of collection and commemoration, which is just the good carrier combing regional culture and commercial economy, but throughout the development current situation of tourism products, the exploration of national features and cultural connotation by China's tourism products is insufficient, the commodities are the same, and the craftsmanship that China's tourist commodity market still to be solved. After inspecting tourism commodity market of Guangxi Zhuang area, it's difficult to find tourist commodities with national features, and the so-called souvenirs with national features sold in various regions, except for the different printed names of scenic spots and the different scene, there is no any distinction for the carrier.

Guangxi, such a major tourism province, its folk culture of Zhuang is quite unique among the national minorities in China, and has representative words, instruments, folk festivals, traditional costume and traditional handicrafts, all of which are cultural elements worth of being studied and sorted out. From many aspects such as system, finance and publicity, for folk culture of Guangxi Zhuang, Guangxi district party committee and governments conduct a mass of protective work, and reach prominent performance, and strengthen the protective consciousness of folk culture. To spread essential Zhuang culture and transform it to commercial value has become the Guangxi research direction of scholars in recent years.

\section{MAIN MATTERS EXISTING IN TOURIST COMMODITIES DEVELOPMENT OF GUANGXI ZHUANG.}

Nowadays, confronted with rapid development of tourism industry, how to transform intangible ethnical culture into tangible business products? How to spread ethnical culture comprehensively and multi-dimensionally? How to directly publicize tourist industry?

How to let business product becomes the business card of tourism publicity? These problems are a direction of worthy of being pondering over for the development of tourist commodities, while main problems existing in Guangxi Zhuang tourist commodities manifest:

1. Tourist commodities of Guangxi Zhuang culture lack of characteristics and creativity, and the excavation on ethnical culture element is not thorough, and the Zhuangcharacteristics system is not bright, so during applying, some of them are easy to mix with others elements even religious component, and for cultural element of hotchpotch kind, designers often integrate them into the same product, which easily produces cultural misleading.

2. At present the tourist commodity level which can embody ethnical culture type of Guangxi Zhuang is not abundant, and most of tourist commodities all still stay at souvenirs whose aesthetic nature give priority to handwork and decoration, which results in the variety of tourist souvenirs is largely identical but with minor difference but the practicality is not strong, and after travelers buy once they will not have the willing to buy these souvenirs.
3. Tourist commodity is a business card with local color, and how to carry and spread ethnical culture and regional culture through tourist commodities? How to connect commodities and culture naturally and effectively? How to integrate the advanced ideas of product design into the design of tourist commodities?

\section{DEVELOPMENT STRATEGY OF TOURIST COMMODITIES WITH GUANGXI ZHUANG CHARACTERISTICS}

Refer to the successful development and innovation experience of tourism products at home and abroad, Guangxi Zhuang cultural features are applicable as the culture material source for the innovation and development of tourist commodity, and on the purpose of innovating artistic products, combining national features to develop a series of tourist commercial products that are mature, practicable and can bear the weight of Guangxi nationality spirit in modeling composition and use pattern.

1. Ecologically and multi-dimensionally extract Zhuang culture of Guangxi region. For an area especially the region of national minority, the excavation of culture should adapt to geographical environment, living habit, historical development and folk art form. For example, mountains occupy a relatively large proportion for the geographical environment of Guangxi, which is located in subtropical areas, and special Karst landform brings up surroundings of easy to live in mountains and water, and evergreen in four seasons. Industrious and intelligent Zhuang people live in green hills for generations, shores of pretty water breeds special Zhuang folk song culture, and also breeds special forms of folk art such as national pattern, totem, cliff painting, embroidery, wood carving, and architectural image. The excavation of ethnical culture not only includes the existing arts and crafts and graphic character and multi-dimensionally and vividly restores the life style, behavior habit, and the ideology accumulated by ancestor such as understanding and collecting folk forms of arts and crafts, collecting folk literature and music, investigating folk-custom and festival ceremony and cooking culture. Only through multi-dimensionally and meticulously gathering and settlement, under the perspective of multiple nationalities extract and purify special design elements belonging to Zhuang culture.

2 . Use the artistic method to extract and purify originalecology material. Re-excavate, re-sublimate the originalecology material, and schematize \& signify concrete objects, and on the basis of traditional artistic expression condense Guangxi Zhuang elements and let the original-ecology material become forms of art. The derived forms of art can combine with the innovation design of tourism product so as to let tourism product bear the weight of ethnical culture to form a culture industry whose carrier is goods.

3. Integrate the principles of the artistic designing into the design development of tourism products, and embody Zhuang culture factor in a more abundant modern form of art, and design products having good taste, creation and high quality. Put the modeling principle, color principle, designing psychology, and design methodology and combine with scientific product design principle and creative principle of artistic products to develop a series of mature tourism 
commercial products and create the development mode of innovation product suitable for regional characteristics.

\section{The CREATIIVE DESIGN PRINCIPLE Of GUANGXI ZHUANG TOURISM PRODUCTS}

Explore the creative design method of tourism culture product to effectively settle the problems of the insufficient design and deficient- in-innovation or existing tourism culture products. How to treat the relations between traditional culture $\&$ modern product, and regional features \& public goods is an important principle of meeting market requirement, and is a key factor whether the innovation of tourism culture products is successful or not and becoming tourism products which have market value.

\section{A. Capture the Prototype of the Mattes and Embody the National Image Characteristics}

Hand-made artwork in common places, local specialty and tourism products sold in other scenic spot, highlight products themselves but neither regional nor national culture, which leads to a misunderstood equivalence between the concepts of tourism products and local specialties. A good tourism product should be designed with a good image prototype. For example, the mascot "Mr Qi" of "Taipei's National Palace Museum", and see Figure 1, this is at the 80th anniversary when the palace museum is built, which is jointly designed by Taipei "The palace museum" and Italy well-known design brand Alessi, and the designer Jiou Vanoni absorbs the inspiration from the portrait treasured up from museums during the youth times of Qianlong emperor, and creates the mascot "Mr. Qing". The mold "Mr. Qing" merely keep a cap and a clothes, and on the portrait's face, a smiling face is merely kept through symbol design method, so simple and lovely, and integrating the philosophy of living "old is new", which don't have the reason of letting people dislike him.

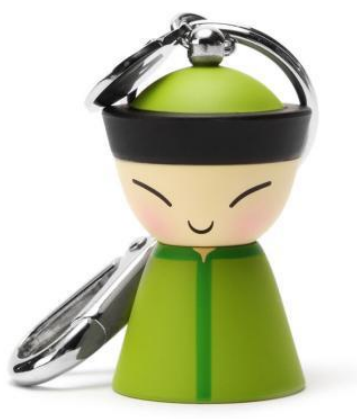

Fig. 1. Mr. Qing

Designing the tourism products of Guangxi Zhuang requires an experienced application of the image elements of Zhuang, for example, the most influential image of Guangxi folk song culture is Liu Sanjie, and during creation, Liu Sanjie image can be explored to conduct product design. Once capturing prototype material, all kinds of work can be easy, so as the design; once the serialization development of products are easily conducted, the economic benefit will be formed, in addition to adopting the existing economic benefits, it is possible to develop and form a virtuous circle. In order to design the aesthetic requirement of conforming to modern people especially the young generation, select to develop and explore the cultural prototype, this contributes to form a good product brand image and pave a road to the commercialization promotion of tourism products.

\section{B. Emphasize the Life Characteristics of Folk-Custom and Increase the Spiritual Moral of Products}

A good implied meaning of image can meet the demands for spiritual beauty appreciation of human, and it requires fully using excavating, extracting and purifying the ethnic elements and materials with specific and implied meanings or adaptable to specific festival occasions, in addition to putting them into the design and conception of products to promote the cultureadded value of tourist commodities.

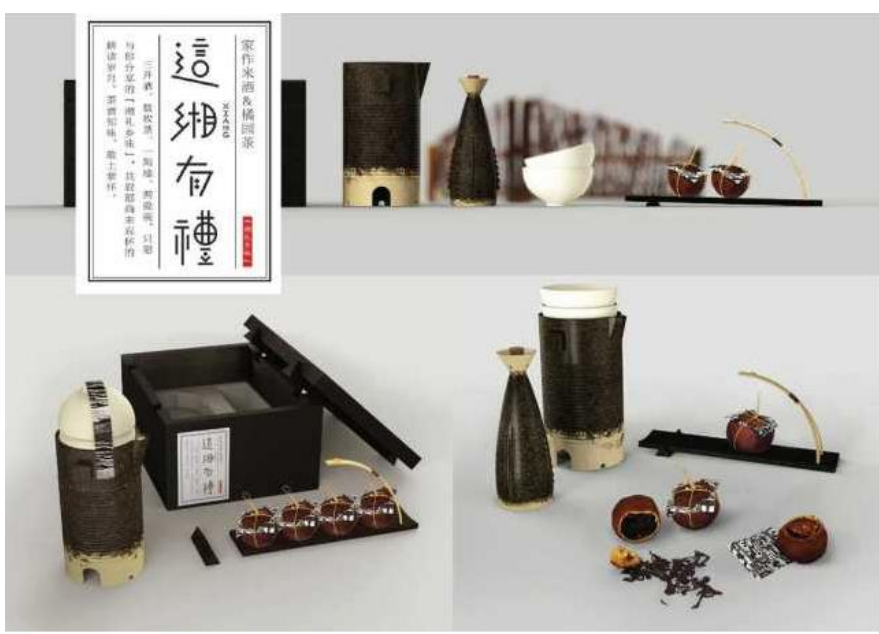

Fig. 2. Hunan gift for you

For example, see the package of "Hunan gift" as shown in Fig.2, it is a set of packaging vessel design whose object is Hunan cultivated tea and rice wine, and the core idea is expressing emotion and reaching ceremony, of which, garden cultivated tea package get the characteristics of "seeking tea between tea and orange with a slight orange incense", following the design of tangerine and fruits, which lets users get the experience of traditional cooking culture in Hunan folk. Here it's emphasized that people can produce resonance with products, which results from the experience of life, and when extracting and purifying ethnic elements all-roundly and multidimensionally find the details of life of ethnic minority, experience life atmosphere, understand concepts of life, for example, in festival occasions, products with representative folk-custom pack and design. In various festivals of Guangxi the most representative is "March Three" song festival, and in this festival it is conventional to eat "five-color glutinous rice", which contains the good meaning of festival reunion, through the design of idea packing, the folk food, as the tourism product, can spread ethnical culture and let consumers sensuously taste Zhuang festival flavor, and mentally feel the auspicious wish of Zhuang people. 


\section{Seek A Breakthrough in the Function of Product Design}

On the premise of product design of modern travel commodity, bring forth new ideas to the operational mode and design procedures of traditional products of ethnical culture, through the way of expansion, recombination, and integration extend the design of products in use function and increase the use value of tourism products. The core problem remained to be settled for the innovation of functions of tourism products is to find a new product carrier or change the use function of original products to meet the new needs of consumers, which can be realized by extending the practicality of travel development and widening travel and the aesthetic design integrating local culture, for example, at present many international first-line brands are doing the improvement products for Chinese culture and handmade sweater for LV weave bags and Hermes, and see Fig.3.

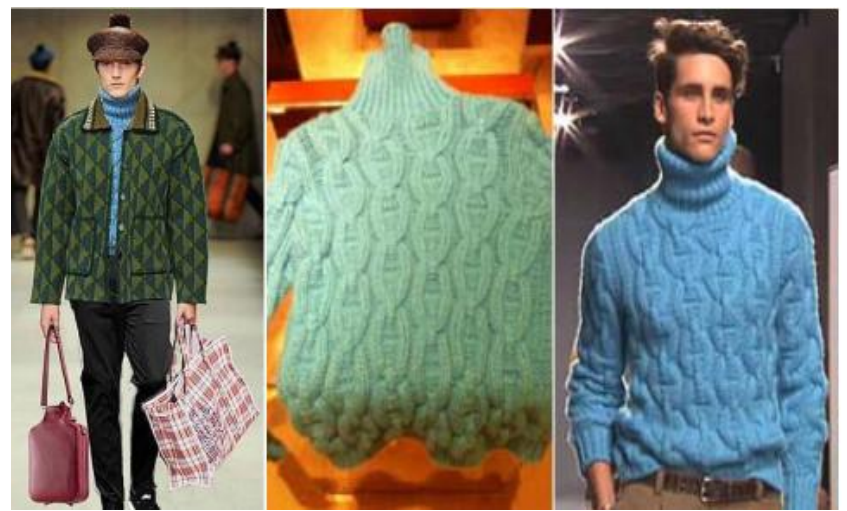

Fig. 3. Hot - water bag, LV weave bag and Hermes handmade sweater )

\section{Seek Innovation from the Appearance of Product Design}

With products as a carrier, integrate the culture of regional ethnic through product design method, such as bionics design, similarity design, variation modeling design and reshaping modeling to let products have a sense of moderns and conform to the aesthetic sense of modern people. For example, see Fig.4, for sticky notes of Chinese blue and white porcelain, designers apply modeling tactics like abstraction and generalization to re-design the original stereoscopic image, consider stationery commodities as product positioning, and mutate them, and during the use process, according to self-characteristics of sticky notes, supplement the original shape, and let products stereoscopic, and at the same time, add the aesthetic taste of arts. In pointed designing Guangxi tourism products, some common methods of product design are tried for pertinent designing Guangxi tourism products. For example, variation method is existing cultural heritage or artifact related to tourist industry such as the regular and purposeful variation for building, sculpture and vessel to finally get the design procedure of creative products. When the design meets the bottleneck, and through changing the form, color, structure, textures, voice and odor of original products or change design method like use pattern, which often gets unexpected creative effect.

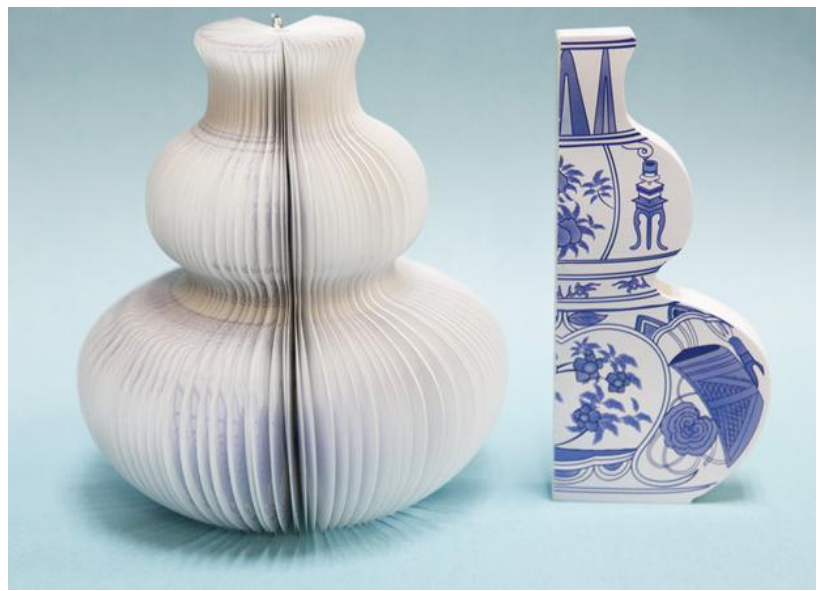

Fig. 4. Sticky note of blue and white porcelain)

\section{E. Concept Innovation of Tourism Culture Products}

The key of innovation of tourism products concept lies in skillfully integrating the artistic connotation and life concept in traditional culture and during designing the interaction between product and user can be started with, and pays close attention to the experience of products and users' emotion, and keep a reservation for the abstraction of ideology in an appreciable way. Products themselves have local cultural characteristics, and at the same time, during the process of using products the users are guided to fulfill some kind of procedures and add a kind of ceremonial sense, or the products can create a kind of special cultural atmosphere to let people produce a kind of association of ceremonial sense. For example, for the pencil design in Figure 7, consider ethnic elements of Guizhou area as a design point, in use procedure ingeniously take advantage of the needed planning procedure construct a kind of consciousness and association whose design is novel. The design of tourism products only accurately grasp the new feature, new fashion and development trend of travel activities, aiming at the need to conduct design, develop only by this can design commercial products that are suitable for markets.

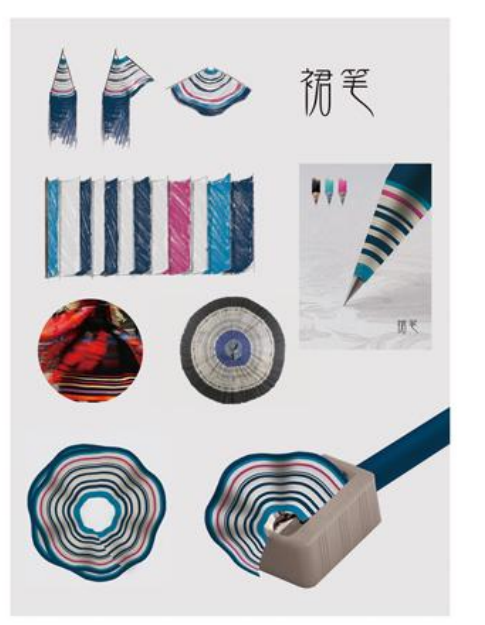

Fig. 5. Excellent works of "Absolute Guizhou" originality competition) 


\section{CONCLUSION}

The design quality of tourism commodities is subject to whether it can integrate the traditional culture and each part of products, and if the kind of integration is naturally linked and reasonably matched, then thus design is deemed as successful. The tourism product design with Guangxi Zhuang characteristic, and the key point of which is to settle the contradiction between traditional culture and modern technology, location character and public universality in order to perfectly join and match. The purpose of innovation design method exploration on manufacturing tourism products special for Zhuang people of Guangxi is to keep the permanent nature of nature, and at the same time, pay close attention to the progressiveness, extension, abutment and multi-element so as to effectively eliminate these contradictions. While excavating the ethnical culture in Guangxi area, integrating the protection $\&$ inheritance and innovation $\&$ development, further promote the integration of traditional arts and crafts products into modern life, based on protecting the diversity and peculiarity of tourism products, through innovation method,; on other hand, based on protecting arts and crafts, it promotes the development of new technique, new process, and new products and enhances the additional value of products through increasing artistic content and taking advantage of the design principle of specialized products; in addition, it conducts active exploration for designing tourism products that carry forward the history and culture of Guangxi and standing out regional characteristics.

\section{REFERENCES}

[1] Wang Wenyu. Method Research of Innovation Design of Tourism Culture Product[J].Packaging Engineering. 2015,36 (14):124-127.

[2] Mu Rongbing and Deng Yilin. Influence of Liu Sanjie Culture in Increasing the Design Quality of Tourism Products[J].Packaging Engineering. 2013, 34(12): 98-101.

[3] Zhu Guangqian. The Beauty of Silence [M] Nanjing: Jiangsu Literature and Art Publishing House, 2010

[4] Qiu Jia-jia, YANG Yan-shi.The Product Innovation Design Method Based on Ancestral Form[J].Packaging Engineering, 2014, 35 (10) : $46-49$.

[5] Liu Fafa. Tourism Product Development Current Situation and Innovation Countermeasure Study in Territory of Nationality [J].Heilongjiang National Series, 2007,02:54-57 